\title{
JUVENTUDE E POLÍTICAS PÚBLICAS: ENTRE PROIBIÇÕES, TRABALHO SUB- REMUNERADO E NOVAS PRÁTICAS DE SOCIABILIDADE
}

\author{
Cezar Bueno Lima
}

\begin{abstract}
RESUMO
As transformações econômicas e socioculturais em curso tendem a aprofundar a crise de legitimidade de políticas púbicas que optam por medidas de controle e integração juvenil, devido à crença no efeito dissuasivo da intimidação criminal e recomendação moral à aprendizagem de profissões subalternas. 0 objetivo analítico deste artigo é indagar até que ponto a atual política de proibição às drogas e de inserção juvenil no mercado de trabalho reforçam a continuidade de ações oficiais de recorte classista e etiquetadora, seja porque subestimam a influência cultural do capitalismo avançado na construção dos planos de vida da juventude pobre, seja porque não consideram como legítimos a existência de espaços democráticos autônomos para que os próprios jovens formulem e encaminhem soluções aos problemas que lhes dizem respeito.
\end{abstract}

Palavras-chave: Juventude. Políticas públicas. Trabalho. Cultura punitiva.

\footnotetext{
${ }^{1}$ Professor Doutor da Pontifícia Universidade Católica do Paraná/Campus Curitiba, Brasil. czarbueno@gmail.com
} 


\title{
YOUTH AND PUBLIC POLICIES: BETWEEN PROHIBITIONS, UNDERPAID WORK AND NEW PRACTICES OF SOCIABILITY
}

\begin{abstract}
Current economic and sociocultural changes tend to deepen the crisis of legitimacy related to public policies that establish control measures and youth integration due to the belief in the dissuasive effect of criminal intimidation and the moral recommendation to learn menial occupations. The analytical aim of this article is to investigate the extent to which the current policy of drug prohibition and youth inclusion in the labor market reinforce the continuity of official actions of classist and labeling perspectives, either because they underestimate the cultural influence of advanced capitalism in the construction of the life plans of poor youth or because they do not consider as legitimate the existence of autonomous democratic spaces for youth themselves to formulate and guide solutions to their problems.
\end{abstract}

Keywords: Youth. Public policies. Work. Punitive culture.

$\mathrm{E}$ ste artigo parte de premissas teóricas e pesquisas empíricas exploratórias com o intento de enfatizar que as políticas públicas de repressão criminal e oferta de aprendizagens subalternas, como forma de inclusão juvenil no mercado de trabalho, enfrentam enormes resistências por parte do seu públicoalvo. Do ponto de vista conceitual, a inoperância de tais medidas pode ser analisada com base na persistência de valores morais e decisões políticas incompatíveis com a dinâmica econômica e sociocultural do capitalismo contemporâneo.

Também se verifica, como parte dessas mesmas medidas, a utilização do conceito ampliado de violência, ou seja, um conjunto de saberes e estratégias de poder para fins de reprodução da violência física e simbólica, consideradas legítimas por parte dos grupos sociais investidos de poder político, autoridade legal e titulação acadêmica, autorizados a conceber, elaborar e executar leis criminais e políticas públicas juvenis. Estas elites, instaladas nos aparelhos de Estado e devotas à gestão racional-burocrática da sociedade, tendem a desqualificar a capacidade de pensamento, ação e elaboração autônoma dos próprios sujeitos que constituem o foco de preocupação governamental.

0 atual contexto socioeconômico e cultural oferece inúmeras possibilidades de realização individual e encoraja cada um a se valer de suas próprias forças para 
dar sentido à existência. Instituições tradicionais como a família, tidas até há pouco tempo como fonte privilegiada de controle social, perdem centralidade, uma vez que os interesses e valores idealizados pelos pais já não servem como sólida referência aos filhos. No lugar dos costumes e rituais de iniciação do passado, impõe-se uma nova e fluída relação de interesses econômicos, políticos e socioculturais urbanos e cosmopolitas, organizados a partir de identidades grupais fluídas, delimitadas e autorreferenciais.

A antiga ética moral familiar - que impunha dever ao trabalho, disciplina, horário fixo, subordinação e respeito à pirâmide de mando - torna-se incompatível no nível atual de expansão da produção, diversificação e radicalização do consumo. Segundo Sennett (2006, p. 134), o processo de produção vigente exalta 0 "valor de pequenas diferenciações concebidas e executadas de maneira rápida”. A informatização da produção e os arranjos organizacionais flexíveis multiplicaram as possibilidades de as mercadorias atenderem necessidades subjetivas distintas no campo da emoção, da identidade e do relacionamento. Para Scheerer, o jogo articulado entre grande mídia e propaganda jovem busca persuadir o universo juvenil a valorizar "coisas aparentemente inúteis" instigando-o a buscar "aventura, autorrealização e experiências especiais." (SCHEERER, 2004, p. 111).

Em relação à crítica anticapitalista, tornou-se mais complexo definir a cultura juvenil como alienada, pois muitos jovens se apoiam em procedimentos racionais que contabilizam custos e perdas sem, contudo, atribuir grande valor à construção de projetos individuais duradouros. Este modelo de vida, escreve Harvey (1998, p. 49), adere à aceitação do "efêmero, do fragmentário, do descontínuo e do caótico". Sob a hegemonia econômica, política e cultural do livre mercado os jovens amplificam as possibilidades de cálculos e planejamentos flexíveis em termos de estilo de vida, experiências inovadoras e comportamentos radicais. Neste panorama sociocultural, segundo Paulilo e Jeolás (2008, p. 6), sobressaem experiências culturais inovadoras, ligadas ao esporte e lazer, gravidez precoce e consumo de substâncias psicoativas. Juntamente a isso, as desigualdades de distribuição do capital econômico e educacional potencializam a contradição entre aquilo que pais, mães, responsáveis e 0 poder público vislumbram para os filhos, em termos de aprendizagem profissional, sucesso e prestígio social, e os entraves cotidianos que os jovens terão de enfrentar devido a crises econômicas, falta de oportunidade escolar, ameaça do desemprego, precarização do ensino e das relações de trabalho. 
A situação de classe costuma impactar de modo diferente o destino dos jovens brasileiros no mercado de trabalho. Enquanto os filhos recém-formados da classe média podem obter ajuda financeira familiar e retardar a entrada no mercado de trabalho, os filhos das classes subalternas são obrigados a trabalhar mais cedo e a ocupar empregos considerados ruins e mal pagos. Estes jovens pobres e excluídos de ajuda econômica familiar, do acesso ou permanência escolar se tornam incrédulos ao ver que o sonho de emancipação financeira idealizado na vida adulta dificilmente será realizado.

Espremidos pela lógica purificadora do mercado, frações da juventude testemunham a imposição de uma realidade econômica e política na qual as possibilidades de êxito assumem contornos incertos. A mudança de papéis sociais, a disponibilidade de múltiplos estilos de vida associados ao lazer, consumo e realização profissional, condizentes com as expectativas formuladas pelos atores juvenis, vêm acompanhadas da incerteza de inserção no mercado de trabalho. Ao mesmo tempo em que 0 mundo produtor de mercadorias disponibiliza novas experiências de excitação, prazer, entretenimento, aventura e interações virtuais, os governos são forçados a corrigir os excessos do livre mercado e disseminar a cultura de intolerância e etiquetamento em relação à pobreza, como procuramos mostrar a seguir.

\section{Prenúncios da InVERSÃo MORAL do CONCEITO DE POBREZA VIRTUOSA}

Se até por volta dos anos de 1980, o fato de alguém ou algum grupo viver ou cair temporariamente na pobreza não significava o perigo imediato de contágio moral, etiquetamento e segregação territorial, as décadas seguintes foram marcadas por opções políticas neoliberais que exigiram reestruturação econômica, ataque aos direitos sociais e um formato de Estado mais policial e menos condescendente em relação aos pobres. Neste período, a política de responsabilização da pobreza impôs a obrigação de contrapartida aos indivíduos que recebem benefícios assistenciais, forçando-os a frequentar cursos de reciclagem e a realizar trabalhos comunitários. A nova arquitetura do Estado/empresa exige das autoridades governamentais metas de superávit fiscal, crescimento econômico, privatização do Estado e ampliação da retórica criminal como estratégia de controle social.

Em situações marcadas por incertezas, instabilidade social e perda de confiança na representação político-institucional, os governos optam por alternativas antidemocráticas como forma de sensibilizar e refrear o medo das 
classes médias urbanas. Em função disso, afirma Wacquant (2001, p. 18), as autoridades políticas se comprometem a normatizar 0 trabalho assalariado precário e localizar, na figura dos andejos, maltrapilhos, pedintes, desempregados ocasionais ou estruturais, a fonte desestabilizadora da ordem social e da segurança urbana.

A classificação de atos e comportamentos considerados bem ou mal sucedidos se subordina - além da capacidade do potencial de consumo econômico - à construção de contrapontos morais empiricamente identificáveis como local de moradia, cor da pele, uso de vestimentas, tipo de linguagem etc., os quais servem para operar a distinção entre 0 certo e desejável, o errado e 0 repugnante. A orquestração do discurso moral e político propõe naturalizar a ideologia da livre concorrência centrada na figura do consumidor soberano e investir na pulverização cultural de comportamentos, autorrealização individualizada e valorização de atividades arriscadas que desafiam o medo e os limites físicos do corpo (esportes radicais).

Paralelamente a isso, a rede midiática e institucional, por onde escoa 0 discurso politicamente correto, recomenda a interdição e reprovação de ações e comportamentos vistos como perigosos e arriscados, sobretudo, quando provocam lesões físicas ou escolhas rotuladas de mau gosto que danificam o corpo, incitam a desobediência e externalizam opções não recomendáveis como a embriaguez, a gravidez precoce e o consumo de drogas (PAULILO; JEOLÁS, 2008).

Em face desta dualidade de valores morais contrapostos, muitos jovens submetidos às metas culturais de sucesso econômico e que, porém, devido a uma constelação de fatores, violam os meios considerados legítimos de obtê-las, entram na lista colecionadora de desvios, perigos e contágio moral. Esta clientela de desajustados sociais justifica a produção de discursos, saberes e práticas institucionais que declaram os benefícios da obediência àqueles que prometam mudar de vida e submeter-se à aprendizagem e execução de ocupações moralmente valorizadas pelo Estado e seus ortopedistas sociais (LIMA, 2009, p. 199-209).

É importante lembrar que os anos de 1990 foram igualmente marcados pelo surgimento e luta de diversos setores da sociedade civil que pressionaram 0 poder público a reconhecer problemas sociais específicos que afetam a juventude. Segundo Andrade $(2010$, p. 7) a abertura de diálogo entre governo, movimentos sociais, partidos políticos, ONGs, pastorais, entre outros, permitiu em 2004 a construção de uma agenda comprometida na superação de conceitos e "ações 
tradicionais" limitadas a oferecer garantia de proteção à juventude portadora de "vulnerabilidades sociais". No ano seguinte, a institucionalização das políticas públicas dirigidas aos jovens permitiu a criação da Secretaria Nacional da Juventude (SNJ) com o seguinte objetivo:

Promover a integração e a transversalidade das ações e programas federais de juventude existentes em diversos órgãos do governo federal, e o Conselho Nacional de Juventude (Conjuve), órgão de articulação entre o governo e a sociedade civil, consultivo e propositivo (ANDRADE, 2010, p. 8).

Em 2007, o governo federal reformulou e readequou as ações anteriores em um só programa denominado Programa Nacional de Inclusão de Jovens (ProJovem Integrado), com o objetivo de desenvolver modalidades de gestão compartilhada entre a Secretaria Nacional de Juventude, Ministérios do Trabalho e Emprego, Educação e Desenvolvimento Social e Combate à Fome (ANDRADE, 2010, p. 8). Neste período, as políticas públicas de juventude (PPJ) foram classificadas como: a) universais - políticas dirigidas a toda a população, visando o estímulo à educação, ao trabalho e à renda, à assistência social, à cultura e ao lazer etc, b) atrativas - pois englobam os pontos de cultura, segurança e 0 combate à violência (que, mesmo não sendo dirigidas especificamente à juventude, possuem maior incidência sobre ela) e c) exclusivas, sobretudo no que diz respeito à criação do ProJovem Integrado, programa cujas políticas específicas são dirigidas aos jovens entre 15-29 anos (ANDRADE, 2010, p. 10).

Apesar de os adolescentes figurarem como sujeitos de direitos, o desafio da sociedade e dos mentores das políticas públicas é reverter a crença institucionalmente arraigada de que o investimento no ensino de aprendizagens profissionais pouco rentáveis, além de funcionar como anteparo ao desemprego, é pouco suficiente para atrair amplos setores da juventude urbana, incluindo os autores de atos infracionais. Contudo, o marco histórico da legislação atual (que reconhece os jovens como sujeitos de direitos e institui políticas públicas especificas para 0 setor) mostra-se, ainda, incapaz de superar a tensão entre aquilo que tais políticas almejam e o sentimento de indiferença ou recusa que habita 0 imaginário dos jovens supostamente beneficiados pelos programas governamentais. Em muitos casos, a falta de interesse e rejeição às recomendações oficiais para que os jovens aprendam alguma profissão, poderia 
ser explicada a partir do lugar de vivência e o significado que os jovens atribuem ao sentido de "vencer na vida".

0 reconhecimento oficial de que muitos jovens precisam de políticas públicas específicas, devido à condição estrutural de pobreza e exclusão escolar, não legitima, por parte do governo, qualificar a juventude pobre como seres predestinados a aprender e executar tarefas que, via de regra, lhes nega possibilidades efetivas de cidadania e realização pessoal. É preciso admitir que frações da juventude brasileira não recusam, por certo, 0 interesse e a necessidade de aprender e executar alguma profissão na estrutura social da qual fazem parte, mas gostariam de ter voz ativa no processo decisório de escolha profissional.

\section{POLITIZAÇÃO JUVENIL DA MORAL QUE PRECONIZA DEVER AO TRABALHO}

A maioria dos jovens sabe formular suas aspirações e possui capacidade de identificar e atribuir valor e prestígio diferenciado às profissões mais valorizadas nas sociedades contemporâneas. 0 que está em jogo não é, por certo, uma menor propensão de a juventude subalterna frequentar a escola ou nutrir menor senso de dever profissional em relação aos seus pares da classe média, mas conforme diversos escritos formulados por Foucault e Bourdieu², uma manifestação de recusa às relações de poder-saber que, por meio da aprendizagem de profissões subalternas, mantém a distribuição desigual de capital cultural e persistem reproduzindo a existência de uma ordem econômica e sociocultural elitista e excludente.

O desconhecimento ou a pouca importância atribuída aos acontecimentos que engendram transformações na maneira de ser e pensar da juventude contemporânea contribui para fomentar preconceitos morais e decisões políticas avessas às noções de interesse, liberdade, dever profissional e projeto de vida juvenil. A esse respeito, é possível notar que os pressupostos morais que vinculam pobreza e obediência às leis do Estado vêm dando lugar a construções identitárias de intolerância que sedimentam, no Brasil e outros países, a ideia de pobre ruim. Submetidos à racionalidade econômica neoliberal, os arquitetos do Estadoempresa e mídia comercial induzem a opinião pública a ver com bons olhos plataformas políticas que acusam o Estado de Bem-Estar de corroer a ética do trabalho e de inculcar junto às classes pobres e iletradas a pedagogia da recusa à oferta de empregos precários e mal pagos disponíveis no setor privado.

\footnotetext{
${ }^{2}$ Sobre este assunto consultar: Bourdieu (2001); Foucault (1982).
} 
No entanto, não é possível abstrair o valor trabalho menosprezando a importância hierárquica que a sociedade e seu respectivo modo de produção atribuem às profissões, em especial, diante de uma juventude seduzida a ver no consumo um poderoso mecanismo de distinção social. Tampouco, é plausível dar crédito acadêmico à explicações que vinculam a perda de interesse e afeição pelo trabalho ao espírito hedonista da juventude contemporânea.

Desde o surgimento da sociedade industrial burguesa exigiu-se dos jovens um longo e árduo ritual de adaptação às funções da vida adulta. Segundo Elias (1994), o processo civilizador impôs exigências inéditas em termos de especialização funcional, diversificação de carreiras e, em consequência, do aumento do tempo de aprendizagem juvenil necessário para o desempenho de tarefas adultas. A intensificação dos processos de reestruturação produtiva, informatização da produção e hegemonia cultural do mercado acirrou a concorrência meritocrática e impôs aos jovens o imperativo da formação e qualificação permanente como forma garantir 0 acesso às profissões que prometem maior ganho e prestígio social. Em face deste quadro, o que está em jogo não é, por certo, explicar porque muitos adolescentes fizeram opção pelo ilegal e aderiram à vida boêmia e hedonista, mas demonstrar qual parcela da juventude poderá obter seletivamente melhores empregos e salários e qual a fração de adolescentes e jovens que, diante de uma série de obstáculos socioeconômicos e educacionais dificilmente conseguirão realizar o sonho de ter uma profissão que simbolize poder e riqueza.

Para isso, é interessante reproduzir os dados resultantes de uma pesquisa sob minha orientaçã $0^{3}$ junto aos estudantes de graduação, oriundos da classe

\footnotetext{
${ }^{3}$ As opiniões dos jovens universitários fazem parte da realização e orientação de projetos de pesquisa na área de sociologia urbana e juvenil que, desde 2010, venho desenvolvendo junto ao Programa Institucional de Bolsas de Iniciação Científica/PIBIC da PUCPR, em coautoria com professores e alunos bolsistas dos cursos de graduação em ciências sociais, direito, história e serviço social. Os jovens universitários e os adolescentes beneficiários de programas governamentais de inclusão profissionalizante de Curitiba e Região Metropolitana compõem 0 universo de interesse da pesquisa. 0 desenvolvimento dos estudos fundamenta-se na utilização de pesquisa bibliográfica e de campo, com o objetivo de compreender como a juventude, em especial, os adolescentes e jovens das classes subalternas pensam e avaliam as políticas públicas de inclusão juvenil. Os resultados da pesquisa têm sido publicados em congressos ou seminários internacionais, nacionais e regionais de interesse na área como $07^{\circ}$ Encontro Anual da Associação Nacional de Direitos Humanos, Pesquisa e Pós- Graduação/ANDHEP em maio de 2012; 0 "Second ISA Forum of Sociology scheduled for Buenos Aires, Argentina, August 1-4, 2012"; o XI Congresso Nacional de Educação - EDUCERE, o IV Seminário Internacional sobre Profissionalização Docente
} 
média e setores sociais subalternos beneficiados pela criação do Programa Universidade para Todos (PROUNI) ${ }^{4}$.

Tabela 1 - Valor atribuído ao trabalho entre alunos/as de graduação da PUC/PR

\begin{tabular}{|l|l|l|}
\hline & Respondentes & Freq \\
\hline Não respondeu & 3 & $1.6 \%$ \\
\hline $\begin{array}{l}\text { O trabalho é algo fundamental para o jovem, independente } \\
\text { do salário que ele receba }\end{array}$ & 91 & $47.4 \%$ \\
\hline $\begin{array}{l}\text { É justificável a opção pelo trabalho ilegal quando for para 0 } \\
\text { jovem "ganhar mais" }\end{array}$ & 29 & $15.1 \%$ \\
\hline $\begin{array}{l}\text { É preferível ganhar menos sendo honesto que ganhar mais } \\
\text { na trapaça e na ilegalidade }\end{array}$ & 66 & $34.3 \%$ \\
\hline Outros & 3 & $1.6 \%$ \\
\hline TOTAL & 192 & $100 \%$ \\
\hline
\end{tabular}

Fonte: Lima e Castellain (2011, p. 9863).

Quando questionados sobre a importância do trabalho como forma de construção da identidade individual e coletiva, os estudantes universitários demonstram que o trabalho em si é considerado algo mais importante que 0 salário que o jovem recebe para executá-lo. Neste ponto, sobressaem evidências que priorizam uma conduta social de honestidade. Mesmo assim, é pertinente indagar até que ponto as respostas juvenis representam apenas uma visão conservadora e romantizada referente ao trabalho, uma vez que os processos de reestruturação econômica e informatização da produção vêm exigindo mudanças drásticas, não apenas no campo da demanda das profissões, salário e condições de trabalho, mas da própria concepção de trabalho. Outra interpretação das respostas pode vincular a concepção juvenil em relação ao trabalho e à crença social e do Estado de que, na posse do diploma universitário, esses jovens

- SIPD- Cátedra UNESCO e o II Seminário Internacional de Representações Sociais, Subjetividade e Educação - SIRSSE/PUCPR 2013.

${ }^{4}$ O PROUNI foi institucionalizado no governo Lula sob a Lei n. 11096/2005 com a finalidade de conceder, mediante a isenção de tributos às instituições de ensino superior privado, bolsas de estudo parciais e integrais aos alunos de graduação com renda familiar per capita de até 3 salários mínimos. 
ocuparão posições dominantes em termos de emprego, poder e prestígio na estrutura de classes das sociedades contemporâneas. Nesse sentido, percebemos como o diploma de Ensino Superior é entendido como um meio de ascensão social.

Por outro lado, a crença de que o estudo e a especialização profissional possibilitam a ascensão econômica - difundida entre os jovens estudantes de classe média e seus pares pobres beneficiados por programas de inclusão universitária — sequer adentra a imaginação da juventude à margem dos bancos universitários. Nesse sentido, são sintomáticos os altos índices de desistência e evasão presentes no Programa Nacional de Inclusão de Jovens (Projovem).

No âmbito da pesquisa empreendida acerca das políticas públicas para a juventude na contemporaneidade ${ }^{5}$, coletamos os dados que alimentam a tabela seguinte.

Tabela 2 - Alunos ingressantes e desistentes do ProJovem Urbano na cidade de Curitiba-PR, 2013

\begin{tabular}{|l|l|}
\hline SITUAÇÃO DOS ALUNOS & TOTAL DE ALUNOS \\
\hline Inscritos & 600 \\
\hline Desistentes & 200 \\
\hline Matriculados & 490 \\
\hline Frequentando & 150 \\
\hline Recebendo Bolsa & 90 \\
\hline
\end{tabular}

Fonte: Freire e Lima (2013, p. 8).

Comparando-se o número de jovens que se inscreveram e frequentam 0 programa percebe-se a importância de repensar os propósitos e as estratégias

\footnotetext{
5 As informações a seguir fazem parte do projeto de pesquisa de minha autoria intitulado "Juventude contemporânea e políticas públicas", apresentado no Seminário de Iniciação Científica (SEMIC 2012/13) da PUC/PR. Um dos objetivos da pesquisa foi aferir os motivos que estudantes atribuíram para os altos índices de desistência junto ao ProJovem Urbano local. Os dados foram obtidos através da aplicação de um questionário aos jovens que frequentam as aulas nas cinco escolas municipais de Curitiba onde o programa é executado. A coleta de dados ocorreu na primeira quinzena do mês de julho de 2013.
} 
governamentais de criação e execução deste modelo de políticas públicas de inclusão juvenil. A maioria dos jovens consultados afirma que o recebimento de uma bolsa mensal no valor de 100 reais é o principal motivo para a permanência e frequência ao programa. A exclusão de muitos jovens do acesso e obtenção do diploma universitário representa uma séria e constante ameaça de que setores da população juvenil, em situação de vulnerabilidade social, terão de conviver com 0 fantasma do trabalho precário e o subemprego.

\section{DA RECUSA AO SUBEMPREGo À OPÇÃO JUVENIL PELO TRABALHO DECENTE}

A lógica cultural do capitalismo avançado choca-se com as perspectivas da juventude urbana uma vez que é improvável que a política econômica em curso consiga democratizar as metas de consumo acessíveis a todos no plano midiático. Neste sentido, é de se esperar o distanciamento e maior ceticismo juvenil em relação às políticas públicas, que vêem com otimismo o emprego simultâneo de medidas punitivas e cursos profissionalizantes, porque muitos jovens estão longe de obter os bens culturalmente valorizados nas sociedades contemporâneas.

Para ilustrar as afirmações em questão é interessante observar os resultados de outra pesquisa de campo com minha participação, coordenada pela sociológica Marcilene G. de Sousa do Instituto de Defesa dos Direitos Humanos (IDDEHA/PR). A pesquisa foi realizada em 2011 junto aos adolescentes em situação de pobreza e vulnerabilidade social matriculados no Ensino Médio das escolas públicas da cidade de Curitiba e Região Metropolitana. 0 objetivo do estudo foi saber o que os adolescentes e jovens residentes em bairros pobres e com elevado índice de vulnerabilidade social pensam sobre violência, drogas e políticas públicas nos locais onde moram.

A pesquisa qualitativa envolveu 17 grupos focais de adolescentes e jovens com idade entre 16 e 24 anos matriculados nas escolas públicas de ensino nos períodos diurno e noturno. Cada grupo focal da pesquisa contou com a presença de seis estudantes de ambos os sexos e registrou a participação de um total de 100 alunos matriculados no ensino médio. Em termos de participação no mercado de trabalho, gênero e cor dos entrevistados, mais da metade (51\%) disseram trabalhar no momento da pesquisa, 53\% responderam pertencer ao sexo feminino, 49\% afirmaram ser negros (pretos e pardos) e 44\% disseram ser brancos. 0 quadro abaixo expõe, em ordem de importância, as sugestões 
elencadas pelos jovens para resolver os problemas que mais lhes afetam na vida em comunidade:

Tabela 3 - Sugestões de melhoria de vida entre os estudantes pesquisados nas escolas públicas do ensino médio em Curitiba e Região Metropolitana.

\begin{tabular}{|l|l|}
\hline $1^{0}$ & Mais emprego e mais estágio \\
\hline $2^{0}$ & Maior investimento no aumento das vagas no trabalho (pouca oportunidade de trabalho) \\
\hline $3^{0}$ & 0 Jovem precisa trabalhar mais cedo \\
\hline $4^{0}$ & Melhorar o salário do jovem no mercado de trabalho \\
\hline $5^{0}$ & $\begin{array}{l}\text { Melhorar a qualidade dos empregos ofertados aos jovens (oposto de trabalho sujo e } \\
\text { subalterno) }\end{array}$ \\
\hline
\end{tabular}

Fonte: Souza (2011, p. 50).

0 quadro sintetiza a ordem de prioridade dos adolescentes em situação de pobreza e vulnerabilidade social a respeito de temas como emprego, salário e qualidade das profissões disponíveis no mercado. As opiniões juvenis obtidas afirmam a importância do dever ao trabalho, porém, e isto constitui o núcleo de preocupação deste artigo, setores da juventude periférica e foco das políticas públicas parecem não estarem dispostos a aceitar e conviver, de maneira pacífica, tal como ocorrera com seus pares em décadas anteriores, com a situação estrutural de pobreza, exclusão e resignação diante das leis repressivas e assistenciais do Estado. Segundo Jacobo (WAISELFISZ 2013, p. 8), o Brasil registrou entre 1980-2010 aumento de 414\% da mortalidade de jovens entre $15 \mathrm{e}$ 29 anos por armas de fogo.

Uma das opções dos jovens excluídos é cortar caminhos e obter por outros meios 0 acesso aos bens materiais e simbólicos desejados. Para isso, não thes faltam motivações cotidianas inerentes à ideologia produtivista que tenta democratizar o sonho de consumo. Para este propósito, contam, inclusive, com estímulos governamentais que recomendam atitudes de respeito às diferenças, liberdade de escolha e estilos de vida concorrentes, desde que estejam aptos e dispostos a buscar novas experiências, multiplicar as possibilidades de consumo e turbinar o lucro privado. Neste contexto de globalização econômica e polarização social, os governos expandem soluções políticas criminalizadoras na tentativa de garantir a ordem e coibir o aumento da violência juvenil relacionada a tráfico e consumo de drogas. Neste campo, afirma Passetti (2003), o discurso político e 
midiático apoia-se em estatísticas oficiais e na ação policial para construir e localizar, nas figuras do traficante impiedoso e jovem drogado, o núcleo da insegurança e instabilidade social contemporânea.

\section{EFEITOS DA GLOBALIZAÇÃO NA GESTAÇÃO DE POLÍTICAS PROIBICIONISTAS}

Sem menosprezar a dimensão e a complexidade dos contornos econômicos, políticos e organizacionais que convertem as drogas em mito criminal, Hulsman e Cellis (1993) apontam a necessidade de superar o ideário penal reformador (comprometido em aperfeiçoar os aparelhos oficiais punitivos, erguer mais prisões e atribuir aos policiais corruptos as supostas causas dos desvios) das boas intenções proibicionistas. Para os autores, a ausência ou pouca incidência de estudos orientados nos marcos de uma cultura política não punitiva contribui para que a ideologia penalizadora permaneça servindo de modelo legítimo e eficaz de solução dos conflitos juvenis decorrentes das drogas. 0 caráter sincrônico e seletivo do paradigma punitivo leva-o a ignorar o dinamismo irredutível das transformações socioculturais, logo, a não admitir que a realidade das drogas possa ser compreendida, explicada e resolvida de maneira oposta às verdades que sedimentam soluções políticas proibicionistas.

Segundo Baratta (2002), a ação policial limita-se a abordar 0 tráfico e consumo de uma pequena quantidade de drogas tradicionalmente conhecidas como a maconha, o crack e a cocaína. Além disso, as decisões políticas e criminalizadoras do Estado brasileiro na década de 1990 retraíram direitos sociais como o aumento do tempo de serviço com carteira assinada para efeitos previdenciários. Soma-se a isso, a criação da Lei $\mathrm{n}^{\circ}$ 8.072/90, lei dos crimes hediondos, que estipulou o aumento da repressão e encarceramento para uma série de crimes, incluindo o tráfico de drogas. Dentre as imposições da lei criminal, afirma Lima (2009), destaca-se o cumprimento de $2 / 3$ da pena na prisão, impedimento da progressão do regime fechado ao semi-aberto ou aberto, não permissão de fiança e proibição do direito de apelar da sentença em liberdade. Em pouco mais de duas décadas, o relatório anual do Centro de Justiça Global, organizado por Sandra Carvalho (2003), informa que a lei dos crimes hediondos quase duplicou a população prisional no país entre 1995 e 2003 . 0 baixo poder de convencimento e atratividade das políticas de criminalização das drogas e programas de inclusão profissional expostos neste artigo sinaliza que os jovens universitários e os que estão cursando o Ensino Médio em escolas públicas 
não estão dispostos a aceitar o ritual de interdições, castigos e certos tipos de aprendizagem laboral.

\section{DROGAS E O COTIDIANO DA JUVENTUDE UNIVERSITÁRIA}

A despeito de não estarem no campo preferencial da ação da polícia, nem no foco punitivo da mídia criminal os jovens universitários tendem a estabelecer relações de proximidade, convivência e distintos graus de tolerância em relação às substâncias psicoativas. Um estudo apresentado por Lima e Castellain (2011) junto à comunidade discente da PUCPR mostra que o posicionamento dos alunos de graduação entrevistados, no caso das substâncias psicoativas, contrapõe-se à visão político-midiática criminalizadora, como sugere a tabela a seguir:

Tabela 4 - Opinião de alunos/as de graduação da PUC/PR acerca do consumo de substâncias psicoativas

\begin{tabular}{|l|l|l|}
\hline & Nb.cit & Freq \\
\hline $\begin{array}{l}\text { As drogas devem ser proibidas, o estado mais eficiente e a } \\
\text { polícia menos tolerante }\end{array}$ & 35 & $18 . \%$ \\
\hline Normal que um jovem experimente & 86 & $44.8 \%$ \\
\hline Maior problema é para o jovem que se torna usuário & 28 & $14.6 \%$ \\
\hline 0 problema maior é para as famílias & 21 & $10.9 \%$ \\
\hline O problema maior é social & 21 & $10.9 \%$ \\
\hline Não respondeu & 1 & $0.5 \%$ \\
\hline Outro & 0 & $0.0 \%$ \\
\hline TOTAL & 192 & $100 \%$ \\
\hline
\end{tabular}

Fonte: Lima e Castellain (2011, p. 9860).

*A pergunta formulada sobre as drogas faz referência às seguintes substâncias: maconha, ecstasy, cocaína, crack, LSD, álcool, outras.

As repostas apresentadas apontam fraca correlação entre os discursos oficiais proibicionistas e 0 pensamento dos estudantes ouvidos na pesquisa. Apesar de os dados apresentados não serem passíveis de generalização, é plausível afirmar que setores consideráveis da juventude universitária mostram-se céticos em relação à atual política de controle e repressão às drogas, ao mesmo tempo em 
que parecem estar receptivos a soluções que transfiram a responsabilidade centrada na figura punitiva do Estado-polícia às esferas não criminalizadoras do Estado e setores da sociedade civil.

Neste ponto, é imprescindível que as autoridades responsáveis pela elaboração e execução de políticas públicas para juventude considerem não apenas a importância de estudos e pesquisas focadas na juventude e no universo das drogas, mas apoiem e militem em defesa da ampliação de pesquisas preocupadas em conhecer os motivos que engendram a transformação do pensamento e o modo de agir da juventude atual. Afinal, muitos jovens costumam aproximar ou evitar tais contatos por motivos opostos aos propostos pelo paradigma da proibição e do medo. Esta afirmação está associada à atmosfera sociocultural que legitima a emergência de modelos de sociabilidade capazes de propiciar práticas sociais que funcionem na base do reconhecimento e tolerância mútua.

Segundo Scheerer (2004, p. 110), verifica-se um distanciamento juvenil dos "valores tradicionais de autoridade, obediência, disciplina e esforço", associado à busca do autoconhecimento, autodeterminação, criatividade, agitação e experiências que, na antiga escala de valores eram classificados como comportamentos proibidos, marginais e moralmente torpes. A tabela abaixo mostra como o consumo regular de substâncias psicoativas não é visto tão negativamente pela população juvenil estudada. Nela fica evidente o quanto 0 uso de drogas faz parte do cotidiano desse segmento populacional.

Tabela 5 - Consumo de substâncias psicoativas entre alunos/as de graduação da PUCPR.

\begin{tabular}{|l|l|l|}
\hline & Nb.cit & Freq \\
\hline Não respondeu & 4 & $2.1 \%$ \\
\hline Usa & 101 & $52.6 \%$ \\
\hline Já fez uso & 4 & $25.0 \%$ \\
\hline Alguém da família usa ou já fez uso & 67 & $34.9 \%$ \\
\hline Amigos usam ou já fizeram uso & 13 & $67.7 \%$ \\
\hline TOTAL & 192 & \\
\hline
\end{tabular}

Fonte: Lima e Castellain (2011, p. 9861). 
Os números da tabela 5 enfatizam que a maioria dos jovens universitários usa, já fez uso ou afirma que alguém da família ou do círculo de amizade faz ou já fez uso de alguma substância psicoativa. As declarações juvenis a respeito do consumo próprio ou convívio pessoal com as substâncias psicoativas apontam para a democratização do uso e proximidade de convivência da comunidade universitária com diversos tipos de substâncias psicoativas. Tal fato aponta para a necessidade de iniciativas político-jurídicas de revisão das legislações proibicionistas. É importante dizer que algumas iniciativas legais não criminalizadoras já fazem parte da estrutura política e normativa do país. A permuta dos conceitos de crime/pena para os de ato infracional/medida sócioeducativa está prevista no Estatuto da Criança e do Adolescente (ECA) o qual, apenas em última instância, recomenda a aplicação da medida de internação (BRASIL, 2002).

Na mesma direção, a nova legislação Anti-Drogas (Lei $n^{\circ} 11.343 / 06$, art.28) (BRASIL, 2006) optou pela despenalização do "consumidor ocasional", visando retirar os jovens consumidores da classe média da mira policial. No entanto, esta legislação confere poder discricionário à polícia para que esta, ao interceptar 0 jovem pobre comercializando pequenas quantidades de drogas ilícitas, o enquadre como traficante e abra caminho para que o judiciário impute-lhe pena mínima de cinco anos de prisão. Por isso, escreve Boiteux (2006), a nova legislação duplicou as cifras de encarceramento de adolescentes e jovens inseridos no tráfico ilegal de drogas. Segundo a autora, a desigualdade de classe funciona como critério legitimador da violência perpetrada pelo o Estado e consentida pela classe média contra setores marginalizados do ponto de vista econômico, étnico e de gênero.

Apesar dos avanços contidos no ECA e na atual legislação antidrogas, tais dispositivos ainda preveem a necessidade do encarceramento e o monopólio de peritos legais para decifrar a lei e executar as medidas judiciais. Entre pessoas desconhecidas, afirma Christie (2004, p. 12) "os funcionários oficiais se convertem na única alternativa de controle". Nessa perspectiva, os atos juvenis que caem nas mãos da polícia e dos agentes vinculados aos aparelhos de justiça se reduzem facilmente em "delitos e delinquentes". Isso poderia ser diferente se houvesse 0 reconhecimento da existência legítima de diversos contextos sociais que permitam o envolvimento e a participação ativa da vítima, do ofensor e demais interessados.

Os sistemas sociais ao nível local, quando marcados por um processo intenso de comunicação interna, permitem obter mais informações sobre as pessoas neles envolvidas. No ambiente familiar, muitas vezes é comum que 
crianças e adolescentes se comportem de uma forma que seria vista como criminosa no ambiente público. Situações corriqueiras (como o dinheiro que some da carteira, brigas e destruição de pertences familiares, 0 excesso ocasional do consumo de álcool, etc.) não são rotuladas como crimes porque os pais e familiares não costumam ver esses casos como delitos e nem seus filhos como delinqüentes. Ao contrário, geralmente os pais conhecem bastante seus filhos e sabem que, para além dos eventuais problemas, estes já lhes demonstraram situações de generosidade como "cuidar dos irmãos", executar tarefas em casa, compartilhar momentos de alegria, angústias, tristezas, entre outros. Por isso, os filhos e parentes próximos são "praticamente imunes à etiqueta da lei penal" (CHRISTIE, 2004, p. 13).

Quando os conflitos assumem dimensão social e transcendem o campo familiar é igualmente possível considerar o objetivo da reparação a qual, por meio da mediação comunitária, possibilita soluções sem o estigma da prisão e do etiquetamento penal. Neste caso, as presenças do autor da infração, da vítima, dos familiares, da comunidade afetada e demais terceiros poderão (longe do exclusivismo da justiça burocrática e onerosa do Estado) atribuir responsabilidades e viabilizar o processo sociojudicial mais adequado para cada caso.

\section{ConcluSÃo}

0 contraponto teórico-empírico em condições de superar o discurso credor de um Estado criminalmente forte, aliado a crenças pedagógicas em cursos profissionalizantes carentes de legitimidade juvenil, requer a opção políticoacadêmica na busca de soluções que concebam as drogas como uma questão irredutível de saúde pública e de saberes e ações que não se limitam a ouvir as reclamações da clientela desviante e que, antes, auxiliem os próprios jovens e suas comunidades de referência no encaminhamento dos conflitos que lhes dizem respeito.

Diante de uma realidade econômica e sociocultural que provoca revoluções de comportamento e solapa a credibilidade de valores e instituições tradicionais, é urgente pensar em políticas públicas e pesquisas acadêmicas comprometidas em soluções que se aproximam da maneira como os jovens, sobretudo os que se encontram na situação de vulnerabilidade social, autores e vítimas de violência física e simbólica, formulam suas visões de mundo, rejeitam fórmulas prontas e 
reivindicam novos padrões de sociabilidade, considerados legítimos perante seus pares e sua comunidade local.

$\mathrm{Na}$ medida em que as instituições sociais, em especial, o Estado, se disponham a conferir legitimidade a discussões e deliberações vindas das organizações sociais de base abrem-se, ao menos, dois caminhos promissores para a solução pacífica dos conflitos. Primeiramente, as próprias instituições serão levadas a repensar e retificar seus discursos e práticas focadas no universo juvenil contemporâneo e, em segundo lugar, a democracia de base comunitária alargará os provedores de significado, conferindo legitimidade e reconhecimento a vozes e sujeitos que ainda hoje são pensados de cima para baixo por burocratas e peritos sociais supostamente dotados de uma consciência moral e científica superior.

\section{REFERÊNCIAS}

ANDRADE, Carla Coelho de. Juventude como questão social $e \quad o$ jovem como sujeito de políticas públicas no Brasil. Disponível em: < http://debates.fundap.sp.gov.br/.>. Acesso em: 26 set. 2010.

BARATTA, Alessandro. Criminologia crítica e crítica do direito penal: introdução à sociologia do direito penal. 3. ed. Rio de Janeiro: Revan, 2002.

BOITEUX, Luciana. A nova lei antidrogas e 0 aumento da pena do delito de tráfico de entorpecentes. Boletim do Instituto Brasileiro de Ciências Criminais (IBCCrim), São Paulo, ano 14, n. 167, p. 8-9, out. 2006.

BOURDIEU, P. Os três estados do capital cultural. In: NOGUEIRA, M. A.; CATANI, A. (Org.). Escritos de educação. 3. ed. Petrópolis: Vozes, 2001.

BRASIL. Lei $n^{o}$ 8.069, de 13 de julbo de 1990. Estatuto da criança e do adolescente. Brasília: CONANDA, 2002.

BRASIL. Lei $n^{\circ} 11.343$, de 23 de agosto de 2006. Institui o Sistema Nacional de Políticas Públicas sobre Drogas -Sisnad; prescreve medidas para prevenção do uso indevido, atenção e reinserção social de usuários e dependentes de drogas; estabelece normas para repressão à produção não autorizada e ao tráfico ilícito de drogas; define crimes e dá outras providências. Disponível em: <http://www.planalto.gov.br/ccivil/_Ato2004-2006/2006/Lei/L11343.htm.>. Acesso em: 5 dez. 2010. 
CARVALHO, Sandra (Org.). Direitos humanos no Brasil 2003: relatório anual do Centro de Justiça Global. 2003. Disponível em: <http://www.global.org.br/portuguese/arquivos/JGRA2003.pdf> . Acesso em: 6 ago. 2006.

CHRISTIE, Nils. Una sensata cantidad de delito. Buenos Aires: Del Puerto, 2004.

ELIAS, Norbert. A sociedade dos indivíduos. Rio de Janeiro: J. Zahar, 1994.

FREIRE, Joice Aparecida; LIMA, Cezar Bueno de. Políticas públicas para jovens não universitários. 2013. Relatório Final apresentado ao Programa Institucional de Bolsas de Iniciação Científica (PIBIC 2012/13), Pontifícia Universidade Católica do Paraná, Curitiba, 2013.

FOUCAULT, M. Microfísica do poder. Rio de Janeiro: Graal, 1982.

HARVEY, David. Condição pós-moderna: uma pesquisa sobre as origens da mudança cultural. 7. ed. São Paulo: Loyola, 1998.

HULSMANN, Louk; CELIS, Jacqueline Bernat de. Penas perdidas: o sistema penal em questão. Rio de Janeiro: Luam, 1993.

LIMA, Cezar Bueno. Jovens em conflito com a lei: liberdade assistida e vidas interrompidas. Londrina: EDUEL, 2009.

LIMA, Cezar Bueno; CASTELLAIN, Mirian. Juventude, políticas públicas e cultura punitiva: entre o reconhecimento de novos padrões de sociabilidade à persistência do etiquetamento. In: SEMINÁRIO INTERNACIONAL DE REPRESENTAÇÕES SOCIAIS, SUBJETIVIDADE E EDUCAÇÃO (SIRSSE), 10., 2011. Curitiba. Anais... Curitiba: PUC, 2011. Disponível em: < http://educere.bruc.com.br/CD2011/pdf/6167_3715.pdf.>. Acesso em: 18 jul. 2012.

PASSETTI, Edson. Anarquismos e sociedade de controle. São Paulo: Cortez, 2003. PAULILO, Maria Angela Silveira; JEOLÁS, Leila Solberger. Jovens, drogas, risco e vulnerabilidade: aproximações teóricas. Serviço Social em Revista, Londrina v. 3, n. 1, p. 39-60, jul./ dez. 2000. Disponível em: <http://www.ssrevista.uel.br/cv3n1.htm. > . Acesso em: 10 dez. 2008.

SCHEERER, Sebastian. Economia dirigida e perspectiva da política de drogas. Discursos Sediciosos: Crime, Direito e Sociedade, Rio de Janeiro, n. 14, p. 105116, 2004.

SENNETT, Richard. A cultura do novo capitalismo. São Paulo: Record, 2006. 
SOUZA, Marcilene G. Pesquisa: juventude, violência, cidadania e políticas públicas em Curitiba e Região Metropolitana. Curitiba: IDDEHA, 2011.

WACQUANT, Loïc. As prisões da miséria. Rio de Janeiro: J. Zahar, 2001.

WAISELFISZ, Julio Jacobo. Mapa da violência 2013: mortes matadas por armas de fogo. 2013. Disponível em: <http://www.mapadaviolencia.org.br/pdf2013/MapaViolencia2013_armas.pdf. $>$. Acesso em: 5 dez. 2013. 